\title{
Changes of phenolic secondary metabolite profiles in the reaction of narrow leaf lupin (Lupinus angustifolius) plants to infections with Colletotrichum lupini fungus or treatment with its toxin
}

\author{
Anna Wojakowska $\cdot$ Dorota Muth $\cdot$ \\ Dorota Narożna • Cezary Mądrzak • \\ Maciej Stobiecki • Piotr Kachlicki
}

Received: 27 July 2012/Accepted: 15 October 2012/Published online: 30 October 2012

(C) The Author(s) 2012. This article is published with open access at Springerlink.com

\begin{abstract}
Plant interactions with environmental factors cause changes in the metabolism and regulation of biochemical and physiological processes. Plant defense against pathogenic microorganisms depends on an innate immunity system that is activated as a result of infection. There are two mechanisms of triggering this system: basal immunity activated as a result of a perception of microbeassociated molecular patterns through pattern recognition receptors situated on the cell surface and effector-triggered immunity (ETI). An induced biosynthesis of bioactive secondary metabolites, in particular phytoalexins, is one of the mechanisms of plant defense to fungal infection. Results of the study on narrow leaf lupin (Lupinus angustifolius L.) plants infected with the anthracnose fungus Colletotrichum lupini and treated with fungal phytotoxic metabolites are described in the paper. The $C$. lupini phytotoxins were isolated from liquid cultures, purified and
\end{abstract}

Electronic supplementary material The online version of this article (doi:10.1007/s11306-012-0475-8) contains supplementary material, which is available to authorized users.

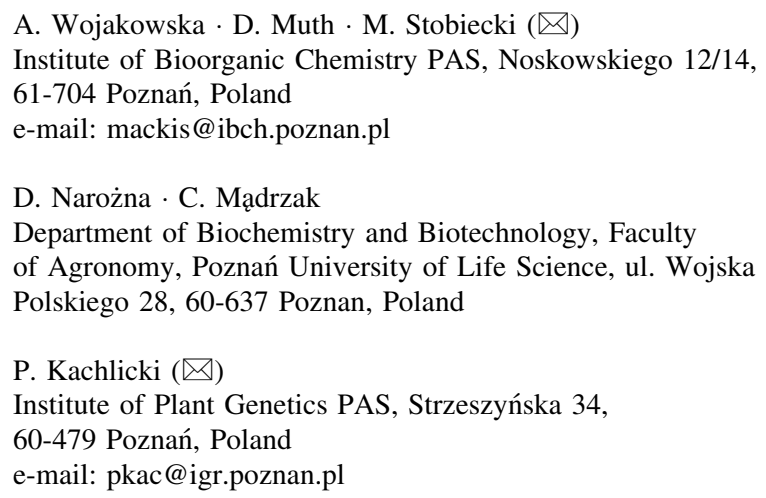

partially characterized with physicochemical methods. Accumulation of secondary metabolites on leaf surface and within the tissues of plants either infected, treated with the fungal phytotoxin or submitted to both treatments was studied using GC-MS and LC-MS, respectively. Substantial differences in isoflavone aglycones and glycoconjugate profiles occurred in response to different ways of plant treatment.

Keywords Colletotrichum lupini - Elicitor - Flavonoids · Infection - Liquid chromatography/Mass spectrometry · Lupinus angustifolius - Secondary metabolite profiling

\section{Introduction}

Flavonoids and their conjugates play an important role in Fabaceae family plants (Gould and Lister 2006). Among other functions, they are defense secondary metabolites synthesized as the result of fungal infection or stresses of other kinds (Bednarek et al. 2003; Lozovaya et al. 2004; Farag et al. 2008, Schliemann et al. 2008; Jasiński et al. 2009). Many classes of these polyphenolic metabolites have an antibiotic activity during plant interactions with pathogenic microorganisms (Dixon and Paiva 1995; Treutter 2006), and these compounds play the roles of phytoalexins or phytoanticipins in plant tissues (van Etten et al. 1994).

Plant defense against pathogenic microorganisms depends on an innate immunity system that is activated as the result of infection. There are two mechanisms of triggering this system: basal immunity activated as a result of microbe-associated molecular patterns (MAMPs) being perceived through pattern recognition receptors (PRR) situated on the cell surface and effector-triggered immunity 
(Boller and Felix 2009). The effector-triggered immunity, sometimes called gene-for-gene resistance, often leads to hypersensitive response of plants and formation of necrotic spots around the infection site due to the programmed cell apoptosis. Effectors of microbial origin, that modulate the plant response to infection, are mainly proteins or peptides, but in some circumstances, low-molecular-weight natural products may also play this role (Wolpert et al. 2002; Allwood et al. 2008; Boller and He 2009; Bednarek and Osbourn 2009; Djamei et al. 2011). Different compounds synthesized by pathogenic microorganisms (e.g. phytotoxins) or being products of pathogen or plant cell degradation are recognized by plant cells as signals for the onset of infection or its danger. Such anticipation of infection is called the defense priming (Conrath 2011) and it has been found to be inherited in the progeny of the infected plant (Luna et al. 2012). Plant reactions on the biochemical or physiological level and activation of various metabolic pathways depend on the type and origin of these signaling natural products. Different secondary metabolites are synthesized after perception and recognition of the signals originating from plant or pathogenic microorganism elicitors created during the first steps of plant defense reactions (Boller and Felix 2009; Grotewold 2005; Veitch 2009). Biosynthesis of isoflavone and closely related pterocarpan phytoalexins by plants from the Fabaceae family is of interest in this respect. Medicarpin synthesized by plants from the Medicago species, pisatin in Pisum or glyceollins in soybean (Glycine max), and luteone and wighteone in Lupinus are among the best characterized compounds.

Problems connected with various responses of the plant to different elicitors were widely described in the case of Medicago truncatula, the Fabaceae model plant. The yeast extract elicitor and methyl jasmonate, the wound-signaling natural product, were used to create specific responses in the cell cultures. Quantitative and qualitative changes of isoflavones and their glycoconjugates as well as substantial differences at the transcriptional level were observed in the treated cultures (Broeckling et al. 2005; Suzuki et al. 2005; Naoumkina et al. 2007; Farag et al. 2008). It was also demonstrated that various classes of flavonoids play different roles during the symbiotic interaction of M. truncatula plants with the nodule-forming rhizobia (Zhang et al. 2009).

Colletotrichum is a genus of plant pathogenic fungi that causes anthracnose disease of various plant species. The taxonomy of this genus is still not clear and about 60 species are classified within it at present (Kirk et al. 2008); however, the Index Fungorum (www.indexfungorum.org) lists 711 names of its species and subspecies. C. lupini, specific for lupin plants (Nirenberg et al. 2002), is widespread on all continents and has been detected in Poland since 1995 (Frencel 1998). Colletotrichum spp. are known to produce phytotoxic secondary metabolites (García-Pajón and Collado 2003; Mancilla et al. 2009) that, in many cases, induce symptoms on plants similar to those caused by the fungi themselves.

Profiles of isoflavone glycoconjugates, free isoflavone aglycones and phytoalexins in leaves of lupin plants treated with fungal phytotoxic secondary metabolites, plants infected with $C$. lupini fungus, and plants submitted successively to both treatments are compared in this study. The C. lupini phytotoxic metabolites were isolated and partially purified from the fungus liquid culture medium and either sprayed on the lupin plantlets or placed on the surface of wounded leaves with a microsyringe. Profiles of the target flavonoids and their glycoconjugates present inside of plant tissues or exuded to the cuticular layer were recorded with LC-MS and GC-MS systems, respectively. Numerous natural products were recognized unambiguously after comparison of the retention times (RT) and mass spectra of the compounds with those registered for standards. On the other hand, some compounds were only tentatively identified on the basis of the mass spectra recorded during the performed HPLC-ESI/MS/MS analyses, in which $\mathrm{MS}^{2}$ and pseudo-MS ${ }^{3}$ experiments were applied for structural characterization of the natural products.

\section{Materials and methods}

\subsection{Reagents and standards}

Solvents for extraction and LC-MS analyses (methanol, acetonitrile and deionized water) were HPLC or LC-MS grade; derivatization reagents for GC-MS analyses (MSTFA- $N$-methyl- $N$-(trimethylsilyl)trifluoroacetamide, methoxylamine, pyridine) were purchased from SigmaAldrich (Poznań, Poland). Standards of luteolin and isoflavone aglycones were obtained from Extrasynthese (Genay, France) or were isolated from lupins and characterized with different physico-chemical methods in the Laboratory (Franski et al. 1999a, b).

\subsection{Plant material}

Four cultivars of narrow leaf lupin (L.angustifolius $\mathrm{L}$.) were used in experiments (sweet cultivars-Baron, Sonet, and bitter-Karo, Mirela). The seeds were purchased from the Plant Breeding Station Przebędowo, Poland. They were sterilized with $1.5 \%$ potassium hypochlorite for $20 \mathrm{~min}$, washed several times with sterile deionized water and sown in pots with Perlite. Plants (five seedlings per pot) were grown in a greenhouse with controlled temperature $\left(22 / 18{ }^{\circ} \mathrm{C}\right.$ day/night) and light $(16 / 8 \mathrm{~h}$ photoperiod) for 2 weeks. 


\subsection{Colletotrichum lupini cultures and growth}

The fungus $C$. lupini (isolate Col2) was isolated from anthracnose-diseased white lupin (L. albus L.) plants in Przebędowo, Poland, in 1998 and maintained in the fungal collection of the Institute of Plant Genetics, Polish Academy of Sciences. It has been identified according to Nirenberg et al. (2002). Conidial spores of the fungus were placed in a Petri dish with potato dextrose agar (PDA) medium and incubated at $28{ }^{\circ} \mathrm{C}$ for 3 weeks. Spores were collected by flooding the plate with sterile $0.1 \%(\mathrm{v} / \mathrm{v})$ Tween 20 solution, followed by filtration to remove parts of the mycelium. Spore concentrations were determined by counting and a suspension of $2 \times 10^{6}$ spores per ml was used for spraying the plants.

\subsection{Isolation and purification of $C$. lupini phytotoxic metabolites}

Colletotrichum lupini was grown on the modified Fries medium placed in Roux bottles (120 bottles, $200 \mathrm{ml}$ of medium in each) at room temperature for 3 weeks. The culture was filtrated and the filtrate was vacuum-evaporated to about 1.51 . Secondary metabolites were extracted 4 times with 0.51 portions of ethyl acetate. The combined organic phases were evaporated to dryness and the residue was re-dissolved in a small volume of $25 \%$ methanolwater solution. This solution was applied to a reversedphase C18 flash chromatography column $1.5 \times 85 \mathrm{~cm}$ (Sigma-Aldrich, Poznań, Poland). The column was eluted with methanol-water solutions with methanol contents increasing stepwise from 25 to $65 \%$. Fractions of the eluate $(25 \mathrm{ml})$ were collected and a $5 \mu \mathrm{l}$ sample from each fraction was spotted onto needle-punctured white and narrow leaf lupin (L. albus cv. Wat and L. angustifolius cv. Sonet) leaves for the phytotoxicity tests. Fractions containing phytotoxic compounds (causing the development of necrotic spots, eluted with $55 \%$ methanol) were submitted to HPLC-MS analysis and to the preparative HPLC in an attempt to achieve pure phytotoxins. A solution containing $1 \mathrm{mg} / \mathrm{ml}$ of the mixture of the phytotoxic compounds in $10 \%$ methanol was prepared and used for plant elicitation.

Attempts for the structural studies of the above natural products with physicochemical methods (mass spectrometry (MS), UV spectrophotometry, ${ }^{1} \mathrm{H},{ }^{13} \mathrm{C} \mathrm{NMR}$ and correlation COSY, NOESY, HMBC, HSQC spectra) only allowed partial characterization of these compounds.

\subsection{Infection of lupin seedlings with $C$. lupini and elicitation with fungal toxin}

Lupin plants (L. angustifolius) were grown in a greenhouse in pots with perlite, five seedlings per pot for 2 weeks.

\subsubsection{Experiment 1}

The plants at the two-leaf stage ( 2 weeks after germination) were infected with spores of $C$. lupini by spraying of whole plants with the spore suspension $\left(2 \times 10^{6}\right.$ spores $/ \mathrm{ml}$, approximately $5 \mathrm{ml} /$ plant), control plants were sprayed with sterile water. Seedlings were placed in hoods in order to maintain the humidity as high as possible for $24 \mathrm{~h}$ to initiate the infection process and, thereafter, the humidity was maintained at $70 \%$. Leaves were collected $24,48,96$, 168 , and $264 \mathrm{~h}$ after the infection, immediately frozen in liquid nitrogen, and kept at $-80{ }^{\circ} \mathrm{C}$ until the analysis. Three independent inoculation experiments have been performed and the first symptoms of anthracnose were visible 7 days after the inoculation.

\subsubsection{Experiment 2}

The plants at the two-leaf stage were also elicited with phytotoxic secondary metabolites of $C$. lupini using two different methods. In the first experiment ("elicitation 1"E1), $10 \mu \mathrm{l}$ samples of the toxin solution ( $1 \mathrm{mg} / \mathrm{ml}$ in $10 \%$ methanol) were spotted on leaves of the first level of seedlings wounded with a needle. The control plants were wounded and similarly treated with $10 \%$ methanol. For the estimation of the wounding effect, untreated leaves of lupin seedlings were sprayed with $10 \%$ methanol and collected at the same time points. Leaves of different ages (from two levels) were collected separately in three repetitions at various time points. Each repetition consisted of material from three seedlings grown in different pots in order to minimize the influence of the biological diversity. Leaves were collected 12, 24, and $48 \mathrm{~h}$ after the treatment. The second method of elicitation ("elicitation 2"-E2) involved spraying of whole plants with the fungal toxin solution $(100 \mu \mathrm{g} / \mathrm{ml}$ solution in $10 \%$ methanol, approximately $2 \mathrm{ml}$ per plant), control plants were sprayed with $10 \%$ methanol. Leaves were collected after 12, 24, and $48 \mathrm{~h}$.

\subsubsection{Experiment 3}

The last experiment was based on plants at the two-leaf stage sprayed with the $C$. lupini phytotoxic metabolites and, after $48 \mathrm{~h}$, submitted to inoculation with the fungal spores. In this experiment, four types of samples were analyzed: samples from the control plants (sprayed with water or $10 \% \mathrm{MeOH}$ and not inoculated with fungal spores); plants sprayed with the phytotoxins and not infected with the spores; plants subjected to infection without previous elicitation with the phytotoxin; plants subjected to both elicitation and infection. Leaves were collected from plants $216 \mathrm{~h}$ after the elicitation and $168 \mathrm{~h}$ 
after the infection with spores. The plant material was frozen in liquid nitrogen directly after cutting and stored at $-80{ }^{\circ} \mathrm{C}$ until the extraction.

\subsection{Extraction of phenolic secondary metabolites from plant tissues}

Extractions of phenolic secondary metabolites from green parts of the lupin plants were done in two independent ways. For the LC-MS analysis, the frozen leaves $(100 \mathrm{mg}$ fresh weight) were homogenized in $2 \mathrm{ml}$ of $80 \%$ methanol (ball mill MM200, Retsch, Haan, Germany), and the suspension was placed in an ultrasonic bath for $30 \mathrm{~min}$. Luteolin was added to the homogenates as an internal standard. The extracts were centrifuged and the supernatants were transferred to new screw-cupped tubes. The solvent was removed in a vacuum concentrator at room temperature (Savant SPD 121P, Thermo Electron Corporation, Waltham, USA). Samples were dissolved in $300 \mu \mathrm{l}$ of $80 \%$ methanol in water and centrifuged at $10,000 \mathrm{rpm}$ for $10 \mathrm{~min}$, transferred to autosampler vials and immediately subjected to LC-MS analyses.

For GC-MS analysis of compounds present on lupin leaf surface, green parts of lupin plants (five plants for each sample) were washed with $100 \mathrm{ml}$ of $\mathrm{CH}_{2} \mathrm{Cl}_{2}$ for $20 \mathrm{~s}$. The washing time was optimized to avoid damage of the cells, causing a leakage of cytosolic compounds that occurred with a prolonged action of the organic solvent. Collection of surface compounds was done at different time points after elicitation or infection. The obtained solutions were evaporated, then the sample was dissolved in $2 \mathrm{ml}$ of $\mathrm{CH}_{2} \mathrm{Cl}_{2}$ and the volume corresponding to $2 \mathrm{mg}$ of the original dry weight from the each sample was transferred to the Teflon-lined screw-capped vials and taken for further GC-MS analysis. Ribitol ( $20 \mu \mathrm{l}$ of methanol solution at a concentration of $1 \mathrm{mg} / \mathrm{ml}$ ) was added to each sample as an internal standard and a two-stage chemical derivatization procedure was performed. Forty $\mu \mathrm{l}$ of $O$-methylhydroxylamine hydrochloride solution in pyridine $(20 \mathrm{mg} / \mathrm{ml})$ was added to the sample and heated at $40{ }^{\circ} \mathrm{C}$ for $90 \mathrm{~min}$ followed by addition of $70 \mu \mathrm{l}$ MSTFA ( $N$-acetyl- $N$-(trimethylsilyl)-trifluoroacetamide) and heating at $37^{\circ} \mathrm{C}$ for $30 \mathrm{~min}$. The sample was centrifuged at $10,000 \mathrm{rpm}$ for $10 \mathrm{~min}$, transferred to autosampler glass vials and subjected to the GC-MS analyses. Two biological samples were collected from each object and two independent extracts were prepared and analyzed for each sample.

\subsection{Gas chromatography/mass spectrometry}

GC-MS analyses of leaf surface compounds were performed with Agilent $6890 \mathrm{~N}$ gas chromatograph with a 7683 autosampler (Agilent Technologies, Stockport, UK) equipped with a DB-5 column $(30 \mathrm{~m} \times 0.25 \mathrm{~mm}$ i.d., film thickness $0.25 \mu \mathrm{m}$ ) from $\mathrm{J} \& \mathrm{~W}$ Scientific Co. (USA) and coupled to the time-of-flight mass spectroscope (MS-ToF) analyzer from Waters. Helium was used as the carrier gas at a flow rate of $1 \mathrm{ml} / \mathrm{min}$. The $\mathrm{GC}$ oven temperature program was as follows: $2 \mathrm{~min}$ at $70{ }^{\circ} \mathrm{C}$, raised by $10{ }^{\circ} \mathrm{C} /$ min to $300{ }^{\circ} \mathrm{C}$, and held for $15 \mathrm{~min}$ at $300{ }^{\circ} \mathrm{C}$. The total analysis time was $45 \mathrm{~min}$. The injector temperature was $250{ }^{\circ} \mathrm{C}$ and $50 \%$ of the recovered vapor was passed into the chromatography column (split 50). The interface temperature was $230{ }^{\circ} \mathrm{C}$ and source temperature was $250{ }^{\circ} \mathrm{C}$. In-source fragmentation was performed with $70 \mathrm{eV}$ energy. Mass spectra were recorded in the $50-650 \mathrm{~m} / \mathrm{z}$ range and data were analyzed using the Waters MassLynx ver. 4.1.

\subsection{Liquid chromatography/mass spectrometry}

Laboratory procedures for the extraction and analysis of secondary metabolites have been well established in our laboratory (Muth et al. 2008, 2009; Jasiński et al. 2009) and are described in details in the Supporting Information.

\subsection{PCR analysis}

Total RNA was isolated from lupin leaves using SV Total RNA Isolation System (Promega) according to the manufacturer recommendations. The RNA concentration in each sample was measured using the Nanodrop 2000 spectrophotometer at $260 \mathrm{~nm}$. Reverse transcription was performed with $2 \mu \mathrm{g}$ of the total RNA used as the template with Verte M-MLV reverse transcriptase (Novazym) in $20 \mu \mathrm{l}$ reaction mixture with oligo-dT primers. Following the reverse transcription, PCR amplification of cDNA was performed with $1 \mu \mathrm{l}$ of the above reaction mixture, which was used as the template in the GenAmp PCR System 9700 (Applied Biosystem).

The PCR amplifications of the chalcone synthase (CHS), chalcone isomerase $(\mathrm{CHI})$, phenylalanine-ammonia lyase (PAL), isoflavone synthase (IFS) and actin-encoding sequences were performed with primers listed below in the $25 \mu \mathrm{l}$ reactions carried out for 25 cycles with Allegro Taq Polymerase DNA (Novazym). The annealing temperatures were: $52{ }^{\circ} \mathrm{C}$ for the CHS and IFS, and $56{ }^{\circ} \mathrm{C}$ for the PAL and actin primers. The PCR products were analyzed using the agarose gel electrophoresis.

The sequences of the primers:

CHS F 5'-ATCCTGATTTCTACTTCAGA- $3^{\prime}$

CHS R $5^{\prime}$-GGTGCCATATAAGCACAAA- $3^{\prime}$

PAL F $5^{\prime}$-CCAAGTCAATTGAGAGGGAG- $3^{\prime}$

PAL R 5'-CATCTTGGTTGTGCTGCTC- $3^{\prime}$

actin F $5^{\prime}$ - GCATTGTTGGTCCTCCTCG-3'

actin R $5^{\prime}$-TGTGCCTCATCCCCAACATA- $3^{\prime}$ 
IFSR 5'-CACAACAAGACCCTTGATT- $3^{\prime}$ IFSF $5^{\prime}$-GGACCTTACTGGAAGTTCAT- ${ }^{\prime}$

\subsection{Data analysis}

The analysis was done independently for the chosen secondary metabolites and was based on differences observed in LC-MS and/or GC-MS profiles registered between the treated and control plants. Baseline correction and alignment of all extracted mass peaks across all LC-MS analyses were done in MetAlign, developed by RIKILT (Institute of Food Safety, Wageningen University and Research Centre) and provided at www.metlign.wur.nl (Lommen 2009). Statistical analyses were carried out using the Microsoft Excel and MarkerLynx (Waters) was used for the GC-MS results.

\section{Results and discussion}

\subsection{Characterization of C. lupini phytotoxic secondary metabolites}

Colletotrichum lupini secondary metabolites extracted from the liquid culture medium were submitted to reversed-phase $\mathrm{C} 18$ flash column chromatography. In order to monitor phytotoxic fungal metabolites, the column eluate was spotted on leaves of L. angustifolius and L. albus plants. Fractions eluted with $55 \%$ methanol caused the development of necrotic spots appearing on the leaf surface several hours after the application (Figure S1). The HPLC analysis of these fractions revealed the presence of multiple compounds with identical UV absorbance spectra consisting of a single maximum of absorbance at $270 \mathrm{~nm}$. According to the HPLC-MS analysis, these compounds were characterized with different molecular weights, but similar fragmentation patterns (Figure S2). The highresolution MS analysis helped establish the elemental composition of eight compounds, A-H present in the fraction, as shown in Table 1. It is noteworthy that at least some of these natural products were synthesized by the fungus in several isomeric forms that could be resolved using the HPLC (Figure S2). Compound $\mathbf{B}$ with the retention time of 8.54 min was the most abundant among the $C$. lupini metabolites and attempts were made to purify it using the preparative HPLC. However, the resulting sample $(1.2 \mathrm{mg})$ was not sufficiently pure for obtaining a good quality NMR spectra required for the structural characterization. The fraction containing compounds $\mathbf{A}-\mathbf{H}$ obtained after the flash column chromatography was used for the further experiments during plant elicitation with the fungal phytotoxin.
Table 1 Fraction of toxic natural products isolated from the culture medium of the fungus, Colletotrichum lupini-molecular formulas estimated from the $\mathrm{m} / \mathrm{z}$ values of $[\mathrm{M}+\mathrm{H}]{ }^{+}$ions

\begin{tabular}{|c|c|c|c|c|}
\hline \multirow[t]{2}{*}{ Compound } & \multirow{2}{*}{$\begin{array}{l}\text { Molecular } \\
\text { formula }\end{array}$} & \multicolumn{2}{|c|}{$\mathrm{m} / z$ of $[\mathrm{M}+\mathrm{H}]^{+}$ion } & \multirow{2}{*}{$\begin{array}{l}\text { Error } \\
(\mathrm{ppm})\end{array}$} \\
\hline & & Measured & Calculated & \\
\hline A & $\mathrm{C}_{19} \mathrm{H}_{35} \mathrm{NO}_{4}$ & 342.2630 & 342.2639 & 2.73 \\
\hline B & $\mathrm{C}_{19} \mathrm{H}_{33} \mathrm{NO}_{5}$ & 356.2437 & 356.2431 & -1.43 \\
\hline $\mathrm{C}$ & $\mathrm{C}_{19} \mathrm{H}_{35} \mathrm{NO}_{5}$ & 358.2588 & 358.2588 & -0.05 \\
\hline D & $\mathrm{C}_{21} \mathrm{H}_{37} \mathrm{NO}_{5}$ & 384.2733 & 384.2744 & 2.99 \\
\hline $\mathrm{E}$ & $\mathrm{C}_{21} \mathrm{H}_{39} \mathrm{NO}_{5}$ & 386.2896 & 286.2901 & 1.21 \\
\hline $\mathrm{F}$ & $\mathrm{C}_{21} \mathrm{H}_{35} \mathrm{NO}_{6}$ & 398.2536 & 398.2537 & 0.22 \\
\hline G & $\mathrm{C}_{21} \mathrm{H}_{37} \mathrm{NO}_{6}$ & 400.2693 & 400.2694 & 0.04 \\
\hline $\mathrm{H}$ & $\mathrm{C}_{23} \mathrm{H}_{39} \mathrm{NO}_{7}$ & 442.2789 & 442.2799 & 2.36 \\
\hline
\end{tabular}

3.2 LC-MS identification of isoflavones and their glycoconjugates

Isoflavone and flavone glycoconjugates in leaves of L. angustifolius were studied earlier using HPLC-MS (Muth et al. 2008, 2009). Thirty-five flavone and isoflavone mono- and diglycosides partially acylated with malonic acid molecules were recognized in the lupin plant tissue then. Several of these compounds were isobaric or isomeric compounds characterized by a different substitution (hydroxylation and/or methoxylation) of the B ring of the aglycone moieties and the positions of the sugars and acyl groups. Moreover, various patterns of the glycosylation with different sugar substituents (hexoses, deoxyhexoses or pentoses) were observed. During the present research, additional pseudo-MS ${ }^{3}$ experiments were performed during the LC/MS analyses (Abranko et al. 2011). This methodical approach resulted in an unambiguous identification of the aglycones of the glycosylated isomeric natural products (Figure 3S). The application of the Advion Triversa Nanomate unit was especially efficient in the analysis of compounds present in minor amounts and additionally increased the number of the detected flavonoids (see Table 2). In particular, glycoconjugates of the isoflavones, luteone and wighteone, which were identified formerly in Mexican lupins (Stobiecki et al. 2010), but not recognized in the European species, were found during the described experiments. Mono- and diglucosides of these aglycones, some of those acylated with malonic acid molecules were recorded (Table 2). The number of detected flavonoid compounds increased twice-to 72 compounds listed in Table 2 as a result of all described improvements in the analytical approach.

The pattern of acylation of the flavone and isoflavone glycosides with malonic acid was an important factor that had a major impact on the structural variability of the studied compounds. An elucidation of the malonic group 
Table 2 Flavonoid glycoconjugates and free aglycones detected in leaves of narrow leaf lupin (L. angustifolius)

\begin{tabular}{|c|c|c|c|c|c|}
\hline \multirow[t]{2}{*}{$\mathrm{Nr}$} & \multirow[t]{2}{*}{ Rt (min) } & \multirow[t]{2}{*}{ MW } & \multicolumn{2}{|c|}{ Exact mass of $[\mathrm{M}+\mathrm{H}]^{+}$ion } & \multirow[t]{2}{*}{ Compound detected in Lupinus angustifolius leaves } \\
\hline & & & Calculated & Observed & \\
\hline 1 & 2.7 & 594 & 595.1657 & 595.1705 & Genistein $C$-diglucoside \\
\hline 2 & 3.3 & 448 & 449.1078 & 449.1088 & $2^{\prime}$-hydroxygenistein 7 -O-glucoside $\mathrm{e}^{\mathrm{a}, \mathrm{b}}$ \\
\hline 3 & 3.4 & 696 & 697.1611 & 697.1605 & $2^{\prime}$-hydroxygenistein diglucoside malonylated $(\mathrm{I})^{\mathrm{a}, \mathrm{b}}$ \\
\hline 4 & 3.5 & 432 & 433.1129 & 433.1122 & Genistein 8 - $C$-glucoside $\mathrm{b}^{\mathrm{b}, \mathrm{c}}$ \\
\hline 5 & 3.7 & 680 & 681.1661 & 681.1651 & Genistein $4^{\prime}, 7 \mathrm{di}-O$-glucoside malonylated $(\mathrm{I})^{\mathrm{a}, \mathrm{b}}$ \\
\hline 6 & 3.8 & 680 & 681.1661 & 681.1669 & Genistein $4^{\prime}, 7 \mathrm{di}-O$-glucoside malonylated (II) ${ }^{\mathrm{a}, \mathrm{b}}$ \\
\hline 7 & 3.9 & 756 & 757.2186 & 757.2187 & Chrysoeriol glucoside-xylosylglucoside ${ }^{\mathrm{b}}$ \\
\hline 8 & 3.9 & 782 & 783.1614 & 783.1615 & $2^{\prime}$-hydroxygenistein $4^{\prime}, 7 \mathrm{di}-O$-glucoside dimalonylated ${ }^{\mathrm{a}}$ \\
\hline 9 & 4.0 & 610 & 611.1607 & 611.1610 & Quercetin 3-O-rhamnosylglucoside ${ }^{\mathrm{b}}$ \\
\hline 10 & 4.2 & 518 & 519.1133 & 519.1136 & Genistein 8 - $C$-glucoside malonylated \\
\hline 11 & 4.2 & 464 & 465.1028 & 465.1015 & Quercetin $O$-glucoside \\
\hline 12 & 4.3 & 448 & 449.1078 & 449.1061 & Luteolin 7-O-glucoside ${ }^{\mathrm{a}, \mathrm{d}}$ \\
\hline 13 & 4.3 & 518 & 519.1133 & 519.1138 & Genistein $O$-glucoside malonylated ${ }^{\mathrm{a}}$ \\
\hline 14 & 4.3 & 680 & 681.1661 & 681.1661 & Genistein $O, C$-diglucoside malonylated ${ }^{\mathrm{a}}$ \\
\hline 15 & 4.3 & 842 & 843.2190 & 843.2203 & Chrysoeriol glucoside-xylosylglucoside malonylated (I) ${ }^{\mathrm{b}}$ \\
\hline 16 & 4.3 & 432 & 433.1129 & 433.1136 & Genistein $7-O$-glucoside $\mathrm{e}^{\mathrm{a}, \mathrm{b}, \mathrm{c}, \mathrm{d}}$ \\
\hline 17 & 4.3 & 534 & 535.1082 & 535.1075 & $2^{\prime}$-hydroxygenistein 7 -O-glucoside malonylated $(\mathrm{I})^{\mathrm{b}}$ \\
\hline 18 & 4.4 & 462 & 463.1235 & 463.1230 & Chrysoeriol 8-C-glucoside ${ }^{c}$ \\
\hline 19 & 4.4 & 842 & 843.2190 & 843.2183 & Chrysoeriol glucoside-xylosylglucoside malonylated (II) ${ }^{\mathrm{b}}$ \\
\hline 20 & 4.4 & 680 & 681.1661 & 681.1667 & Genistein diglucoside malonylated $^{\mathrm{b}}$ \\
\hline 21 & 4.5 & 842 & 843.2190 & 843.2217 & Chrysoeriol glucoside-xylosylglucoside malonylated (III) ${ }^{\text {b }}$ \\
\hline 22 & 4.5 & 766 & 767.1665 & 767.1669 & Genistein $4^{\prime}, 7 \mathrm{di}-O$-glucoside dimalonylated $(\mathrm{I})^{\mathrm{a}, \mathrm{b}}$ \\
\hline 23 & 4.6 & 766 & 767.1665 & 767.1662 & Genistein $4^{\prime}, 7 \mathrm{di}-O$-glucoside dimalonylated (II) ${ }^{\mathrm{a}, \mathrm{b}}$ \\
\hline 24 & 4.6 & 534 & 535.1082 & 535.1075 & $2^{\prime}$-hydroxygenistein 7 -O-glucoside malonylated (II) ${ }^{\mathrm{a}, \mathrm{b}}$ \\
\hline 25 & 4.6 & 462 & 463.1235 & 463.1230 & Chrysoeriol $O$-glucoside $(\mathrm{I})^{\mathrm{b}}$ \\
\hline 26 & 4.6 & 448 & 449.1078 & 449.1088 & Kaempferol-3-O-glucoside $\mathrm{e}^{\mathrm{a}, \mathrm{d}}$ \\
\hline 27 & 4.7 & 842 & 843.2190 & 843.2205 & Chrysoeriol glucoside-xylosylglucoside malonylated (IV) ${ }^{\mathrm{b}}$ \\
\hline 28 & 4.8 & 564 & 565.1552 & 565.1551 & Apigenin $O$-xylosylglucoside ${ }^{\mathrm{a}}$ \\
\hline 29 & 4.8 & 518 & 519.1133 & 519.1142 & Genistein $C$-glucoside malonylated \\
\hline 30 & 4.8 & 782 & 783.1614 & 783.1618 & 2'-hydroxygenistein 7-O-diglucoside dimalonylated \\
\hline 31 & 4.8 & 928 & 929.2194 & 929.2209 & Chrysoeriol glucoside-xylosylglucoside dimalonylated (I) ${ }^{\mathrm{b}}$ \\
\hline 32 & 4.9 & 928 & 929.2194 & 929.2201 & Chrysoeriol glucoside-xylosylglucoside dimalonylated (II) ${ }^{\mathrm{b}}$ \\
\hline 33 & 4.9 & 432 & 433.1129 & 433.1131 & Apigenin 7-O-glucoside $\mathrm{e}^{\mathrm{a}, \mathrm{c}, \mathrm{d}}$ \\
\hline 34 & 5.0 & 928 & 929.2194 & 929.2192 & Chrysoeriol glucoside-xylosylglucoside dimalonylated (III) ${ }^{\mathrm{b}}$ \\
\hline 35 & 5.0 & 766 & 767.1665 & 767.1662 & Apigenin $4^{\prime}, 7 \mathrm{di}-O$-glucoside dimalonylated ${ }^{\mathrm{a}}$ \\
\hline 36 & 5.0 & 696 & 697.1611 & 697.1615 & 2'-hydroxygenistein 7-O-diglucoside malonylated (II) \\
\hline 37 & 5.1 & 666 & 667.1505 & 667.1512 & Luteolin xylosylglucoside malonylated $^{\mathrm{a}}$ \\
\hline 38 & 5.1 & 594 & 595.1657 & 595.1665 & Chrysoeriol $O$-xylosylglucoside ${ }^{\mathrm{b}}$ \\
\hline 39 & 5.1 & 548 & 549.1239 & 549.1245 & Chrysoeriol $C$-glucoside malonylated \\
\hline 40 & 5.2 & 534 & 535.1082 & 535.1089 & Kaempferol- $O$-glucoside malonylated ${ }^{\mathrm{a}}$ \\
\hline 41 & 5.2 & 518 & 519.1133 & 519.1124 & Genistein 7-O-glucoside malonylated $(\mathrm{I})^{\mathrm{a}}$ \\
\hline 42 & 5.3 & 650 & 651.1556 & 651.1549 & Genistein 7-O-xylosylglucoside malonylated (I) \\
\hline 43 & 5.3 & 462 & 463.1235 & 463.1234 & Chrysoeriol $O$-glucoside (II) \\
\hline 44 & 5.4 & 518 & 519.1133 & 519.1131 & Genistein 7-O-glucoside malonylated (II $)^{\mathrm{a}, \mathrm{b}}$ \\
\hline 45 & 5.4 & 678 & 679.2233 & 679.2215 & Luteone $O$-diglucoside \\
\hline 46 & 5.5 & 650 & 651.1556 & 651.1551 & Genistein 7-O-xylosylglucoside malonylated (II) ${ }^{\mathrm{b}}$ \\
\hline 47 & 5.5 & 680 & 681.1661 & 681.1678 & Chrysoeriol $O$-xylosylglucoside malonylated (I) ${ }^{\mathrm{b}}$ \\
\hline
\end{tabular}


Table 2 continued

\begin{tabular}{|c|c|c|c|c|c|}
\hline \multirow[t]{2}{*}{$\mathrm{Nr}$} & \multirow[t]{2}{*}{ Rt (min) } & \multirow[t]{2}{*}{ MW } & \multicolumn{2}{|c|}{ Exact mass of $[\mathrm{M}+\mathrm{H}]^{+}$ion } & \multirow[t]{2}{*}{ Compound detected in Lupinus angustifolius leaves } \\
\hline & & & Calculated & Observed & \\
\hline 48 & 5.6 & 518 & 519.1133 & 519.1139 & Apigenin $O$-glucoside malonylated $(\mathrm{I})^{\mathrm{a}}$ \\
\hline 49 & 5.6 & 650 & 651.1556 & 651.1553 & Apigenin $O$-xylosylglucoside malonylated $(\mathrm{I})^{\mathrm{a}}$ \\
\hline 50 & 5.7 & 680 & 681.1661 & 681.1678 & Chrysoeriol $O$-xylosylglucoside malonylated (II) ${ }^{\mathrm{b}}$ \\
\hline 51 & 5.8 & 518 & 519.1133 & 519.1136 & Apigenin $O$-glucoside malonylated (II $)^{\mathrm{a}}$ \\
\hline 52 & 5.8 & 680 & 681.1661 & 681.1681 & Chrysoeriol $O$-xylosylglucoside malonylated (III) ${ }^{\mathrm{b}}$ \\
\hline 53 & 5.9 & 286 & 287.0550 & 287.0547 & $2^{\prime}$-hydroksygenistein ${ }^{\mathrm{a}, \mathrm{b}, \mathrm{c}, \mathrm{d}}$ \\
\hline 54 & 5.9 & 548 & 549.1239 & 549.1253 & Chrysoeriol $O$-glucoside malonylated ${ }^{\text {b }}$ \\
\hline 55 & 5.9 & 662 & 663.2283 & 663.2269 & Wighteone $O$-diglucoside \\
\hline 56 & 6.0 & 680 & 681.1661 & 681.1665 & Chrysoeriol $O$-xylosylglucoside malonylated (IV) ${ }^{\mathrm{b}}$ \\
\hline 57 & 6.1 & 766 & 767.1665 & 767.1660 & Chrysoeriol $O$-xylosylglucoside dimalonylated (I) ${ }^{\mathrm{b}}$ \\
\hline 58 & 6.2 & 766 & 767.1665 & 767.1683 & Chrysoeriol $O$-xylosylglucoside dimalonylated (II) ${ }^{\mathrm{b}}$ \\
\hline 59 & 6.2 & 766 & 767.1665 & 767.1776 & Chrysoeriol $O$-xylosylglucoside dimalonylated (III) ${ }^{\mathrm{b}}$ \\
\hline 60 & 6.5 & 850 & 851.2240 & 851.2225 & Luteone $O$-diglucoside dimalonylated \\
\hline 61 & 6.8 & 748 & 749.2287 & 749.2290 & Wighteone $O$-diglucoside malonylated \\
\hline 62 & 6.9 & 516 & 517.1704 & 517.1701 & Luteone 7 - $O$-glucoside \\
\hline 63 & 5.9 & 834 & 835.2291 & 835.2285 & Wighteone $O$-diglucoside dimalonylated \\
\hline 64 & 7.0 & 764 & 765.2237 & 765.2241 & Luteone $O$-diglucoside malonylated (II) \\
\hline 65 & 7.1 & 270 & 271.0601 & 271.0602 & Genistein $^{\mathrm{a}, \mathrm{b}, \mathrm{c}, \mathrm{d}}$ \\
\hline 66 & 7.2 & 270 & 271.0601 & 271.0603 & Apigenin $^{\mathrm{a}, \mathrm{c}, \mathrm{d}}$ \\
\hline 67 & 7.8 & 603 & 603.1708 & 603.1713 & Luteone $7-O$-glucoside malonylated \\
\hline 68 & 8.5 & 500 & 501.1755 & 501.1749 & Wighteone 7 - $O$-glucoside \\
\hline 69 & 9.8 & 586 & 587.1759 & 587.1767 & Wighteone 7-O-glucoside malonylated \\
\hline 70 & 7.5 & 300 & 301.0707 & 301.0714 & Chrysoeriol $^{\mathrm{a}, \mathrm{c}, \mathrm{d}}$ \\
\hline 71 & 14.4 & 354 & 355.1176 & 355.1178 & Luteone $^{\mathrm{a}, \mathrm{b}, \mathrm{c}, \mathrm{d}}$ \\
\hline 72 & 14.6 & 338 & 339.1227 & 339.1231 & Wighteone $^{\mathrm{a}, \mathrm{b}, \mathrm{c}, \mathrm{d}}$ \\
\hline
\end{tabular}

${ }^{a}$ Identification of aglycone based on mass spectra registered in $\mathrm{MS}^{3}$ mode

b Compounds reported in earlier published papers: Muth et al. (2008; 2009)

${ }^{c}$ PubChem ID numbers of the identified compounds: genistein 8-C-glucoside-44257270; genistein 7-O-glucoside—44257273; chrysoeriol 8-C-glucoside-44258170; apigenin 7-O-glucoside-5280704; 2'-hydroksygenistein-5282074; genistein-5281377; apigenin-5280443; chrysoeriol-5280666; luteone-5281797; wighteone-5281814

${ }^{\mathrm{d}}$ Identification of compound based on comparison with standard

placement on the sugar moieties was not possible only on the basis of mass spectra registered during the LC-MS analyses, so a purification of the compounds and the NMR analyses would be necessary. The application of a rapidresolution LC system assisted with the additional fractionation of the LC column eluate using the TriVersa device permitted an efficient separation of isomers of malonylated isoflavone, flavone and flavonol glycosides, but still no definite conclusions regarding the substitution pattern of these isomeric glycoconjugates with malonyl groups could be drawn. Nevertheless, the possibility to use the off-line mode of obtaining MS spectra using TriVersa, especially in $\mathrm{MS}^{2}$ or pseudo-MS ${ }^{3}$ mode, provided better quality spectra. Profiles of the target flavonoids and their conjugates present in the studied samples, including quantitative changes of positional isomers of malonylated flavonoid glycoconjugates, were elucidated on the basis of the single-ion chromatograms of protonated molecules registered in the MS mode.

\subsection{GC-MS identification of natural products}

Compounds present on the surface of lupin leaves in the wax and suberin layer were analyzed using the GC-MS. Samples were prepared from the control plants as well as from the ones subjected to the infection with the $C$. lupini spores and/or elicitation with phytotoxic metabolites of the fungus sprayed on the plantlets. The cuticle components, such as waxes and secondary metabolites, were washed with methylene chloride from leaves of two high alkaloid ("bitter") and two low alkaloid ("sweet") L. angustifolius cultivars. Conditions of this extraction procedure (organic 
solvent and time of washing) were optimized in order to achieve the maximal yield and avoid a damage of cell walls and membranes causing a leakage of cytoplasm components. The samples were derivatized with trimethylsilyl (TMS) groups to block the polar groups of the molecules and increase the volatility of the studied compounds injected on the GC column (see 'Materials and methods'). Different classes of primary and secondary metabolites: alkaloids, fatty acids and their esters, sterols and isoflavones were recognized in the studied samples on the basis of comparison of the registered mass spectra with the data bases. The most abundant and important group of natural products detected on the lupin leaf surface were the quinolizidine alkaloids (QA). To no astonishment, a substantial quantitative difference in the alkaloid contents (two orders of magnitude) was observed between the sweet and bitter cultivars studied. The 14 detected alkaloids were eluted from the GC column in a wide range of RT due to the presence of the free bases (angustifolin, lupanin and multiflorin) as well as 13-hydroxylupanin esterified with various organic acids (see Table 1S). It is noteworthy that the total amount of alkaloids present in the bitter lupin cultivars was dominated by the 13-hydroxylupanin esters, whereas the non-esterified QA were more abundant in the sweet cultivars. The individual QAs were identified on the basis of their RT and the respective mass spectra in comparison with these obtained for the standard compounds. There were no quantitative differences observed in abundances of QAs in samples prepared from control, C. lupini infected or phytotoxin-elicited plants (data not presented). Among the flavonoid compounds only prenylated isoflavones wighteone and luteone that are known lupin phytoalexins (Ingham et al. 1983) were also detected on the leaf surface of plants infected with the $C$. lupini spores or elicited with its phytotoxic metabolites (Fig. 1). Amounts of wighteone and luteone detected on the leaf surface were much smaller than these of QAs, especially in the case of the bitter cultivars (Mirela and Karo). There was a notable difference between the prenylated isoflavone aglycones found on leaf surface of the infected and elicited plants. While luteone and wighteone were recognized in the former group, only wighteone could be detected on the latter plants. A large increase of the amount of free wighteone was observed on the leaf surface of the phytotoxin-elicited plants in relation to the control as early as $12 \mathrm{~h}$ after the treatment (Fig. 2) when it was 7 times higher and it remained at the elevated level (400\% of the control) after $48 \mathrm{~h}$. It should be noted that neither infection with the fungal spores nor phytotoxin treatment caused any change in presence of flavonoid aglycones other than the prenylated isoflavones on the surface of $L$. angustifolius leaves. Similarly, no changes in fatty acid and sterols were observed as a result of the plant treatment.

\subsection{PCR analysis of phenylpropanoid pathway genes}

Changes in transcription of genes responsible for the key enzymes participating in the isoflavone biosynthesis pathway (PAL, CHS, CHI and IFS) in response to infection with $C$. lupini and treatment with the phytotoxic metabolites of the fungus were studied at different time points. The transcription of the studied genes was monitored after 24 and $48 \mathrm{~h}$ in the case of spraying plants with the phytotoxin solution and, additionally, 96 and $168 \mathrm{~h}$ after infection with the $C$. lupini spores. The level of transcription of three genes (CHS, CHI and IFS) under study increased in the treated plants above the level in the control as a result of both types of plant treatment (Figure 4S), whereas the expression of PAL as well as the positive control actin genes remained on the same level. Additionally, it was found that the transcription of the monitored enzymes was higher in the leaves submitted to the phytotoxin deposition than in the untreated leaves collected from the treated plants (data not presented). On the basis of these data, we can conclude that the regulatory mechanisms of the lupin plant response activated during their interaction with spores and fungal toxin involve induction of the isoflavone biosynthesis pathway.

\subsection{Comparison of profiles of isoflavone glycoconjugates and free aglycones in tissues of lupin plants elicited with toxin or infected with spores}

As it was mentioned previously, different mass spectrometric methods were elaborated for the structural characterization of the studied flavonoid glycoconjugates and for their quantitative analysis. These methods differed in settings of the ISCID (in source collision-induced dissociation) parameters that influenced the relative intensity of the $[\mathrm{M}+\mathrm{H}]^{+}$ions and the fragment ions. While the structural elucidation was based mainly on $\mathrm{MS}^{2}$ and pseudo-MS ${ }^{3}$ experiments, the quantitative analysis was performed in conditions, in which intense $[\mathrm{M}+\mathrm{H}]^{+}$ions were registered. Anyway, a discussion of a biological role of the natural products present in the analyzed samples demands their proper identification. For example, two isomers of malonylated glucosides of 2'-hydroxygenistein (compounds $\mathbf{1 7}$ and $\mathbf{2 4}$ with RT of 4.3 and $4.6 \mathrm{~min}$, Table 2; Fig. 3) and malonylated kaempferol glucoside (compound 40, RT of $5.2 \mathrm{~min}$ ) were isobaric compounds with a molecular weight of $534 \mathrm{Da}$ as identified in the analyzed samples. The abundance of only one $2^{\prime}$-hydroxygenistein derivative (compound 24) was changed substantially as a result of infection or elicitation of lupin plants (Fig. 3).

Three different types of plant treatment were applied during our experiments, in which changes to the contents of 

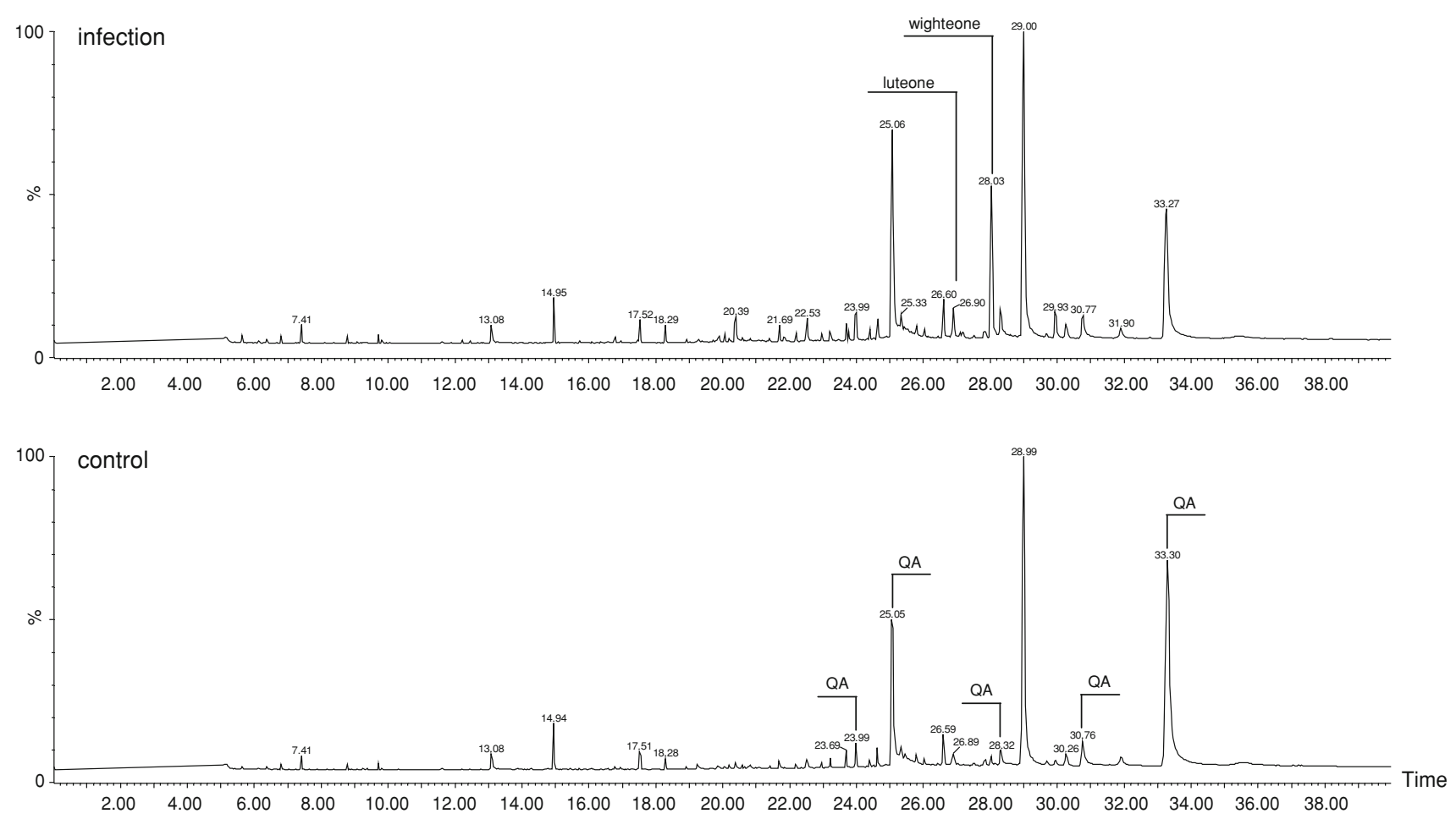

Fig. 1 GC-MS total ion chromatogram registered for cuticle and wax washings of the lupin plantlets (cv. Mirela-bitter) after infection with C. lupini spores (top) and control plants (bottom). Analyses were

isoflavones and their glycoconjugates in tissues of L. angustifolius leaves were studied. Plants were (1) sprayed with the $C$. lupini spore suspension, (2) elicited with the fungus phytotoxic compounds applied either on wounded leaves or sprayed on plants and (3) sprayed with the phytotoxins and with spores $48 \mathrm{~h}$ later. Changes of the studied isoflavonoid profiles were detected as a result of all the treatments applied; however, the plant responses were different and occurred after different times depending on the way of their treatment. Amount of each compound in the studied tissue was calculated using the total intensity of the respective $[\mathrm{M}+\mathrm{H}]^{+}$ion in relation to that of the internal standard (luteolin) and the mass of the sample. The mean values obtained from three biological repetitions, each measured in two chromatographic runs are presented in the Supplementary Materials (Figures 5S-8S). Figures 2, 4, 5 and 6 show the same data as the measured amount of the studied compound in leaves of plants treated with fungal compounds or infected with the $C$. lupini spores in relation to that detected in the control plants.

In the case of infection with spores of $C$. lupini, a maximum response directed to the synthesis of phenolic secondary metabolites was recorded after 7 days (168 h), but the onset of the increased accumulation of these compounds was observed after $24 \mathrm{~h}$ (Fig. 4). Three free isoflavone aglycones ( 2 -hydroxygenistein and two known phytoalexins, wighteone and luteone) were found in tissues performed for two biological samples at two technical repetitions for each sample. The identified QA are listed in Table 1S

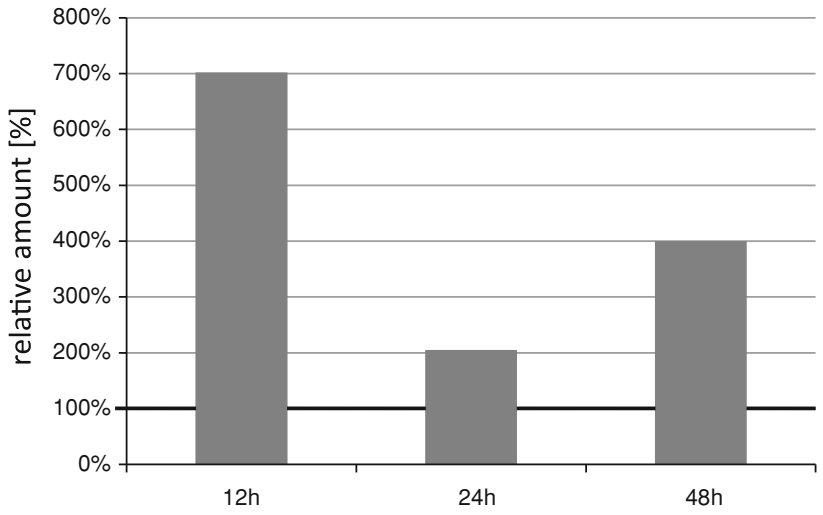

Fig. 2 Contents of wighteone detected in the samples obtained by washing of lupin leaves with $\mathrm{CH}_{2} \mathrm{Cl}_{2}$, obtained at three time points after elicitation $(12,24$, and $48 \mathrm{~h}$ ) of lupin plants (L. angustifolius cv. Sonet) with phytotoxin obtained from cultures of fungus $C$. lupini. The GC-MS measured amounts of wighteone are expressed in relation to that in the control plants $(=100 \%)$. Analyses were performed for two biological samples at two technical repetitions for each sample

in much increased amounts at all studied time points in comparison to these observed in the control plants. In contrast, the amount of genistein was elevated substantially at the last time point of the experiment. In particular, the levels of free luteone observed in leaves of the infected plants after 7 days were more than 50 times higher than these in the control plants. It should be noted that the contents of some isoflavonoid glycoconjugates also 
(a)

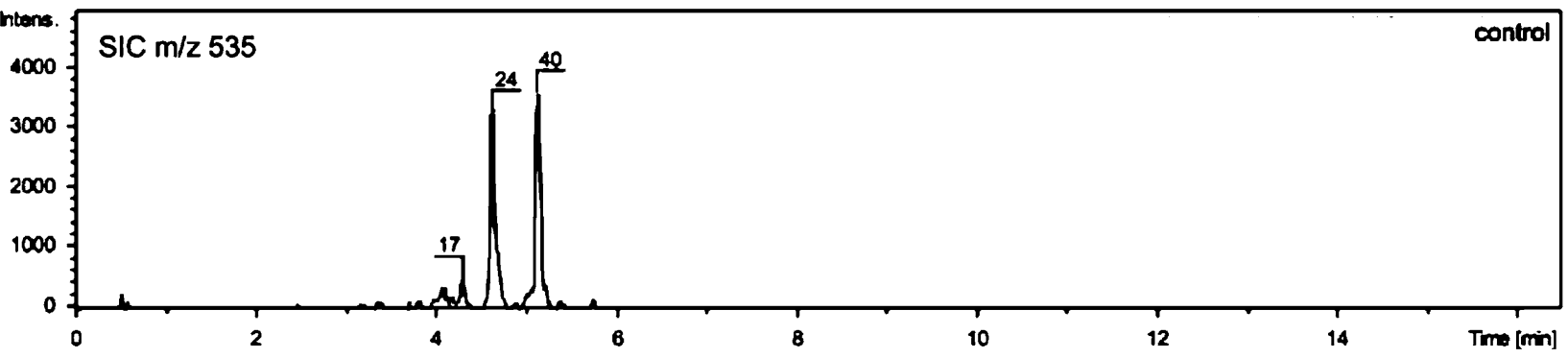

(b)

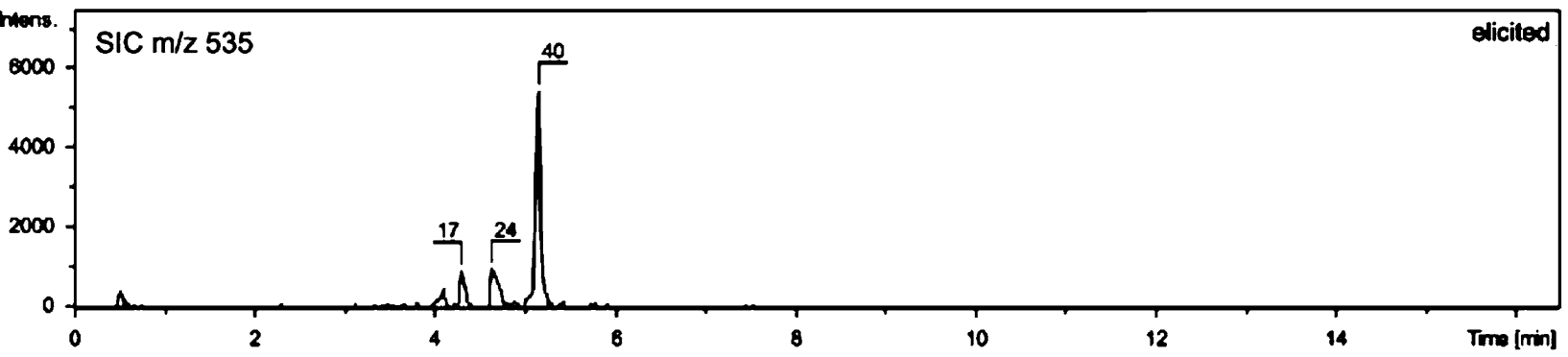

(c)

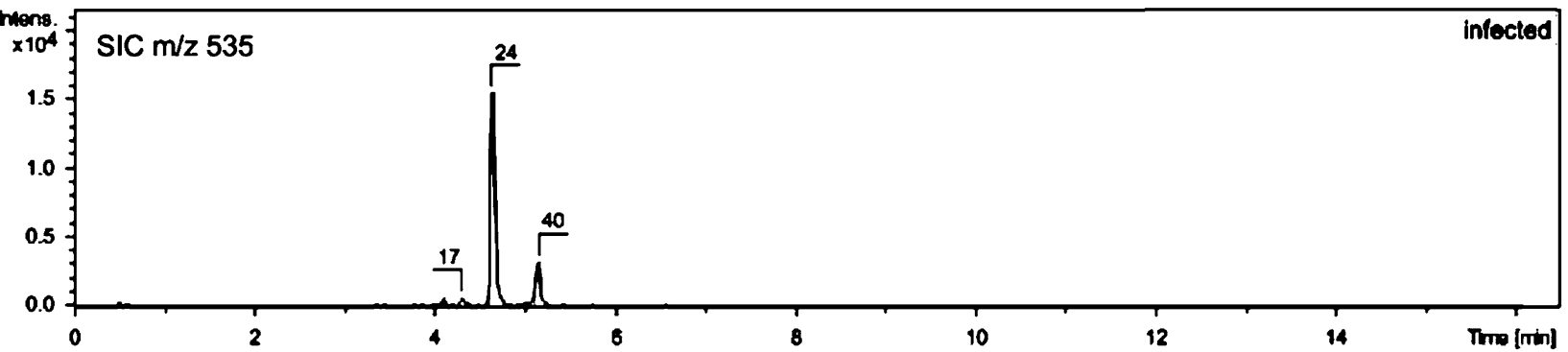

(d)

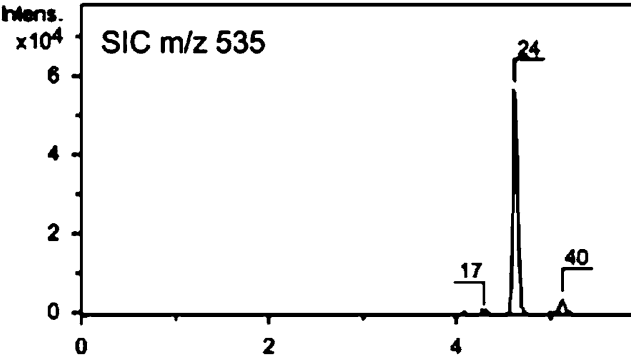

Fig. 3 Single-ion chromatograms $(S I C)$ registered for $[\mathrm{M}+\mathrm{H}]^{+}$ ions at $\mathrm{m} / z, 535$ for malonylated $2^{\prime}$-hydroxygenistein- $O$-glucosides $(\mathbf{1 7}, \mathbf{2 4})$ and their isobaric compound, malonylated kaempferol$O$-glucoside (40) in samples obtained from leaves of sweet cultivar

of narrow leaf lupin L. angustifolius (cv. Sonet). a Control, b elicited, c infected with spores and d elicited and after $48 \mathrm{~h}$ infected with fungal spores lupin seedlings. All samples of plant material were collected 7 days after infection

increased. Interestingly, only one isomeric malonylated 2 '-hydroxygenistein glucoside (compound 24) was observed in an increased amount, whereas another isomer (compound 17) remained on the level observed in the control. Moreover, levels of different wighteone glycoconjugates were also increased shortly after the infection (Fig. 4c) and their amount decreased at the later time points.

Rapid and substantial changes in profiles of isoflavones and their derivatives were observed in the experiments, in which the fungal phytotoxin was applied as an elicitor of the plant response (Fig. 5). Several interesting differences were noted in the reaction of the phytotoxin-elicited plants in comparison to the infected ones. Spraying of plants with phytotoxins caused almost a fourfold increase of the amount of the free wighteone above the levels in the control plants just $12 \mathrm{~h}$ after the "elicitation 2" and this was observed until $48 \mathrm{~h}$ (Fig. 5a). The wighteone level was even higher in plants, in which phytotoxin was deposited on wounded leaves ("elicitation 1", up to $800 \%$ of the control), but some of this should be attributed to the effect of wounding. In the "elicitation 1", the wighteone level increase was observed only in the treated leaves and no 
Fig. 4 Contents of chosen isoflavones and their glycoconjugates detected after infection with $C$. lupini spores of lupin plants (L. angustifolius cv. Sonet), expressed in relation to the control $(=100 \%)$, time points: $24,48,96,168$ and $264 \mathrm{~h}$ after infection. Free isoflavone aglycones: genistein- $[\mathrm{M}+\mathrm{H}]^{+}$at $\mathrm{m} / \mathrm{z}$ 271 (65), 2'-hydroxygenistein$[\mathrm{M}+\mathrm{H}]^{+}$at $m / z, 287(\mathbf{5 3})$, wighteone- $[\mathrm{M}+\mathrm{H}]^{+}$at $\mathrm{m} / \mathrm{z}$ 339 (72), luteone- $[\mathrm{M}+\mathrm{H}]^{+}$ at $\mathrm{m} / \mathrm{z} 355$ (71) (a); isoflavone glycoconjugates (malonylated genistein-7- $O$-glucoside$[\mathrm{M}+\mathrm{H}]^{+}$at $m / z, 519$ - two isomers $(\mathbf{4 1}, \mathbf{4 4})$, malonylated $2^{\prime}$-hydroxygenistein-7-Oglucoside- $[\mathrm{M}+\mathrm{H}]^{+}$at $\mathrm{m} / z$ 535-two isomers $(\mathbf{1 7}, \mathbf{2 4})(\mathbf{b})$; and wighteone glyconjugates: wighteone glucoside$[\mathrm{M}+\mathrm{H}]^{+}$at $m / z, 501(68)$, malonylated wighteone glucoside- $[\mathrm{M}+\mathrm{H}]^{+}$at $\mathrm{m} / \mathrm{z}$ 587 (69), wighteone diglucoside- $[\mathrm{M}+\mathrm{H}]^{+}$at $m / z$. 663 (55), malonylated wighteone diglucoside$[\mathrm{M}+\mathrm{H}]^{+}$at $m / z, 749(61)$ and dimalonylated wighteone diglucoside- $[\mathrm{M}+\mathrm{H}]^{+}$at $\mathrm{m} / z$ 835) (63) (c). Plant material was collected at five time points after infection: 24, 48, 96, 168 and $264 \mathrm{~h}$. The values are averages from LC-MS analyses of three biological samples with two technical repetitions for each one
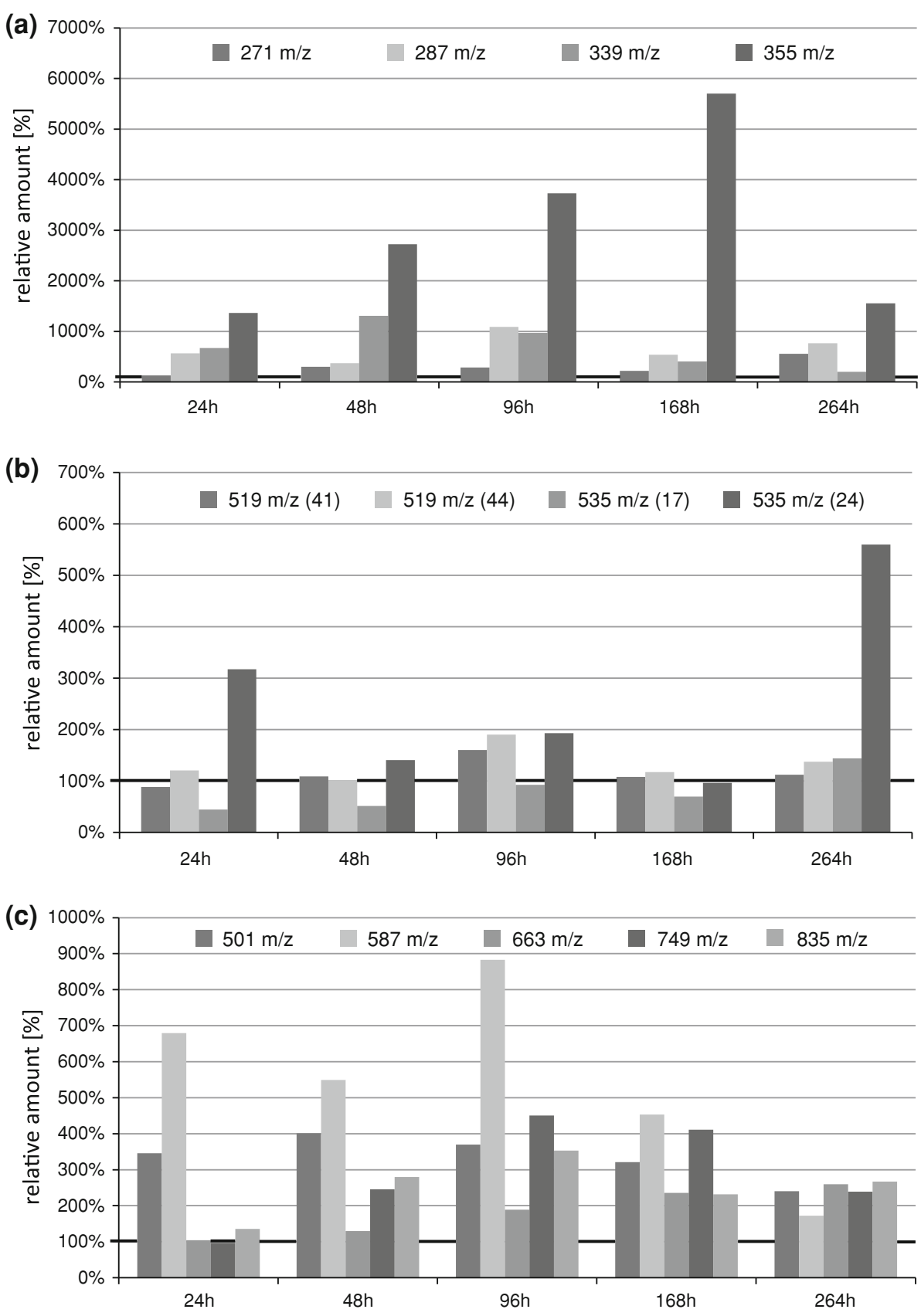

SAR-like effect was observed in the untreated leaves of the elicited plants. The "elicitation 1" did not cause any induction of luteone, the other prenylated isoflavone phytoalexin. Some differences between both types of elicitation "E1 and E2)" effects could be observed in the accumulation of the wighteone derivatives: malonylated and dimalonylated diglucosides (compounds $\mathbf{6 1}$ and $\mathbf{6 3}$, Table 2) and monoglucoside and monoglucoside malonylated (compounds 68 and 69). Amounts of these compounds increased within $12 \mathrm{~h}$ after the "elicitation E1" to $350-600 \%$ of the level in the control plants and then gradually decreased until $48 \mathrm{~h}$ after the treatment. On the other hand, the increase of their amount was slower as a result of the "elicitation E2", but even $800 \%$ of the control level was reached after $48 \mathrm{~h}$ (Fig. $5 \mathrm{~b}$ ).

Accumulation of isoflavone derivatives in response to the elicitation with the phytotoxic metabolites of $C$. lupini and subsequent infection with spores of the fungus was observed in the third described experiment. Plants sprayed with the phytotoxic metabolites were infected after $48 \mathrm{~h}$ and leaves thereof were collected 7 days $(168 \mathrm{~h})$ later. Contents of isoflavones in control plants, plants either only elicited or only infected and plants both elicited and infected were compared at the same time, 9 days (216 h) 
Fig. 5 Contents of wighteone $\left([\mathrm{M}+\mathrm{H}]^{+}\right.$at $\left.m / z, 339-72\right)$ and genistein $\left([\mathrm{M}+\mathrm{H}]^{+}\right.$at $m / z$ 271-65) (a) and wighteone glycoconjugates (wighteone glucoside $[\mathrm{M}+\mathrm{H}]+$ at $\mathrm{m} / \mathrm{z}$. 501 (68), malonylated wighteone glycoside$[\mathrm{M}+\mathrm{H}]^{+}$at $m / z 587$ (69), malonylated wighteone diglycoside- $[\mathrm{M}+\mathrm{H}]^{+}$at $\mathrm{m} / \mathrm{z}$ 749 (61) and dimalonylated wighteone diglycoside$[\mathrm{M}+\mathrm{H}]^{+}$at $m / z$ 835) (63) (b) Natural products detected after elicitation of lupin plants (L. angustifolius cv. Sonet) with the fungal toxin expressed in relation to the control $(=100 \%)$. Elicitation of lupin plants by deposition of the toxin on leaves (point infection)- $\mathrm{E}_{1}$; spraying of the toxin on leaves- $\mathrm{E}_{2}$. Plant material was collected at three time points after elicitation: 12,24 and $48 \mathrm{~h}$. The values are averages from LC-MS analyses of three biological samples with two technical repetitions for each one
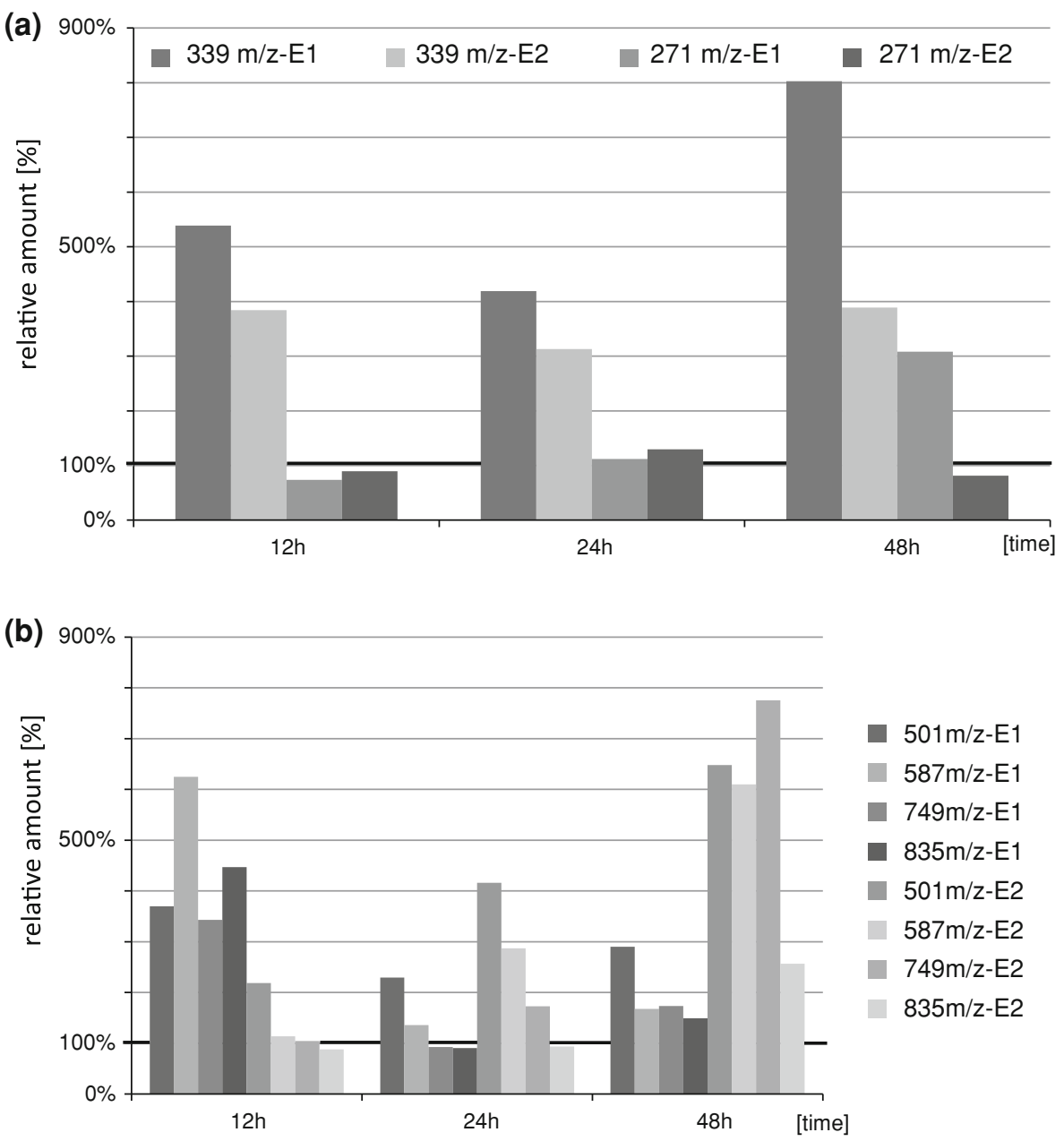

after the start of the experiment. This time was selected as a result of the earlier experiments, in which the highest induction of the metabolite accumulation was observed between 96 and $168 \mathrm{~h}$ after the infection. Genistein and 2'hydroxygenistein were the most abundant free aglycones in leaves of plants infected after the previous elicitation and their contents increased to a level $1600 \%$ higher than those of the control (Fig. 6). Both these isoflavone aglycones were induced to some extent as a result of elicitation or infection performed independently, but the induction observed in plants infected $48 \mathrm{~h}$ after the elicitation was much more pronounced. Similar observation could be made for some specific glycoconjugates of $2^{\prime}$-hydroxygenistein, luteone and wighteone (Fig. 6b). On the other hand, contents of numerous compounds was either not changed or only slightly increased as an effect of the applied treatments of plants.

Analysis of plant reactions during pathogenic microorganism attack or elicitation with various high- or lowmolecular-weight natural products may indicate that different reactions at various molecular levels (RNAs, proteins and secondary metabolites) are developed in the studied plants.
These reactions may differ in various plants due to numerous defense mechanisms developed by plants during their evolution at the perception (MAMP) and recognition (PRR) levels of the natural products signaling the infection by phytopathogens. That is why the response of narrow leaf lupin plants to the infection with the anthracnose fungus spores and to the elicitation with the defined effectors may involve expression of various proteins and further synthesis of different secondary metabolites, due to activation of different enzymes in the metabolic pathways. Induction of the expression of genes involved in the isoflavone biosynthesis pathway as well as increase of the contents of the target natural products, either in the form of the free aglycones or as their glycoconjugates in plants of $L$. angustifolius infected with $C$. lupini fungus, was studied in the experiments described herein. Prenylated isoflavones are known components of lupin defense system. Phytoalexins wighteone and luteone are synthesized by lupin plants as a result of fungal infection (Ingham et al. 1983) and licoisoflavones A and B present in L. angustifolius roots have been shown to deter larvae of pasture scarabs Costelytra zealandica and Heteronychus arator (Lane et al. 1987). It was previously 
Fig. 6 Contents of chosen isoflavones and their glycoconjugates detected in lupin seedlings of 2 weeks old after elicitation $(E)$, infection with $C$. lupini spores $(I)$ or elicitation followed with infection $48 \mathrm{~h}$ after elicitation of lupin plants $(E+I)$ (L. angustifolius cv. Sonet), expressed in relation to the control $(=100 \%)$. On the graphs are presented: relative amounts of free aglycones-genistein$[\mathrm{M}+\mathrm{H}]^{+}$at $\mathrm{m} / \mathrm{z} 271(\mathbf{6 5}), 2^{\prime}$-hydroxygenistein- $[\mathrm{M}+\mathrm{H}]^{+}$at $\mathrm{m} / z$ 287 (53), wighteone- $[\mathrm{M}+\mathrm{H}]^{+}$at $\mathrm{m} / \mathrm{z} 339$ (72), luteone$[\mathrm{M}+\mathrm{H}]^{+}$at $\mathrm{m} / z 355$ (71) (a); isomers of malonylated glycosides of genistein and 2'-hydroxygenistein: (malonylated genistein-7-Oglycoside- $[\mathrm{M}+\mathrm{H}]^{+}$at $m / z, 519$ - two isomers $(\mathbf{4 1}, \mathbf{4 4})$, malonylated $2^{\prime}$-hydroxygenistein-7- $O$-glycoside- $[\mathrm{M}+\mathrm{H}]^{+}$at $\mathrm{m} / \mathrm{z}$ 535-two isomers $(\mathbf{1 7}, \mathbf{2 4})(\mathbf{b})$; luteone glucoside $-[\mathrm{M}+\mathrm{H}]^{+}$at $\mathrm{m} / \mathrm{z}, 517(\mathbf{6 2})$, malonylated luteone glucoside $-[\mathrm{M}+\mathrm{H}]^{+}$at $\mathrm{m} / \mathrm{z} 603(\mathbf{6 7})$, luteone diglucoside- $[\mathrm{M}+\mathrm{H}]^{+}$at $\mathrm{m} / z 679$ (45) and dimalonylated luteone diglucoside- $[\mathrm{M}+\mathrm{H}]^{+}$at $m / z 851(60)$ (c) and wighteone glyconjugates: wighteone glucoside- $[\mathrm{M}+\mathrm{H}]^{+}$at $\mathrm{m} / \mathrm{z} 501(\mathbf{6 8})$, malonylated wighteone glycoside- $[\mathrm{M}+\mathrm{H}]^{+}$at $m / z \quad 587$ (69), and wighteone diglycoside $-[\mathrm{M}+\mathrm{H}]^{+}$at $\mathrm{m} / z \quad 663$ (55), malonylated wighteone diglycoside- $[\mathrm{M}+\mathrm{H}]^{+}$at $m / z 749(61)$ and dimalonylated wighteone diglycoside- $[\mathrm{M}+\mathrm{H}]^{+}$at $m / z$ 835) (63) (d). Control and treated plants were collected at the same time ( 9 days from the start of elicitation)

found (Muth et al. 2009) that wighteone and luteone were accumulated differently in leaves of plants infected with the C. lupini fungus. This observation has been currently supported by finding that only wighteone was found in increased amounts on the surface as well as within leaf tissues of plants that were treated with phytotoxins of the fungus, whereas both wighteone and luteone were induced by the infection.

Treatment of some plant species with low-molecularweight signaling compounds, like salicylic acid or methyl jasmonate (the well-known elicitors of response to biotic stresses), may induce systemic acquired resistance (SAR), as it was observed in the case of $M$. truncatula (Naoumkina et al. 2007; Farag et al. 2008, 2009). However, SAR was not observed in the case of the presently studied deposition of the C. lupini phytotoxic compounds on leaves of L. angustifolius plantlets. On the other hand, the elicitation of lupin plants with these compounds prior to the application of fungal spores caused a much faster and more intense answer of such treated plants than it was observed after only the infection with the spores. An increased synthesis of certain malonylated forms of the isoflavone glycosides was one of the effects observed in the lupin plant response to fungal infection or treatment with fungal phytotoxic compounds. Similar effects were also observed for other plant species from the Fabaceae family that are subjected to biotic or abiotic stress (Lozovaya et al. 2004; Farag et al. 2008, 2009; Jasiński et al. 2009). Isoflavone $O$ malonyltransferases were recently characterized in Medicago truncatula and it was observed that the expression of these genes was stress-inducible (Zhao et al. 2011). However, these genes present in different legume plants do not exhibit sequence similiarities ( $\mathrm{Yu}$ et al. 2008), and monitoring of malonyltransferases in lupin was not yet realized.
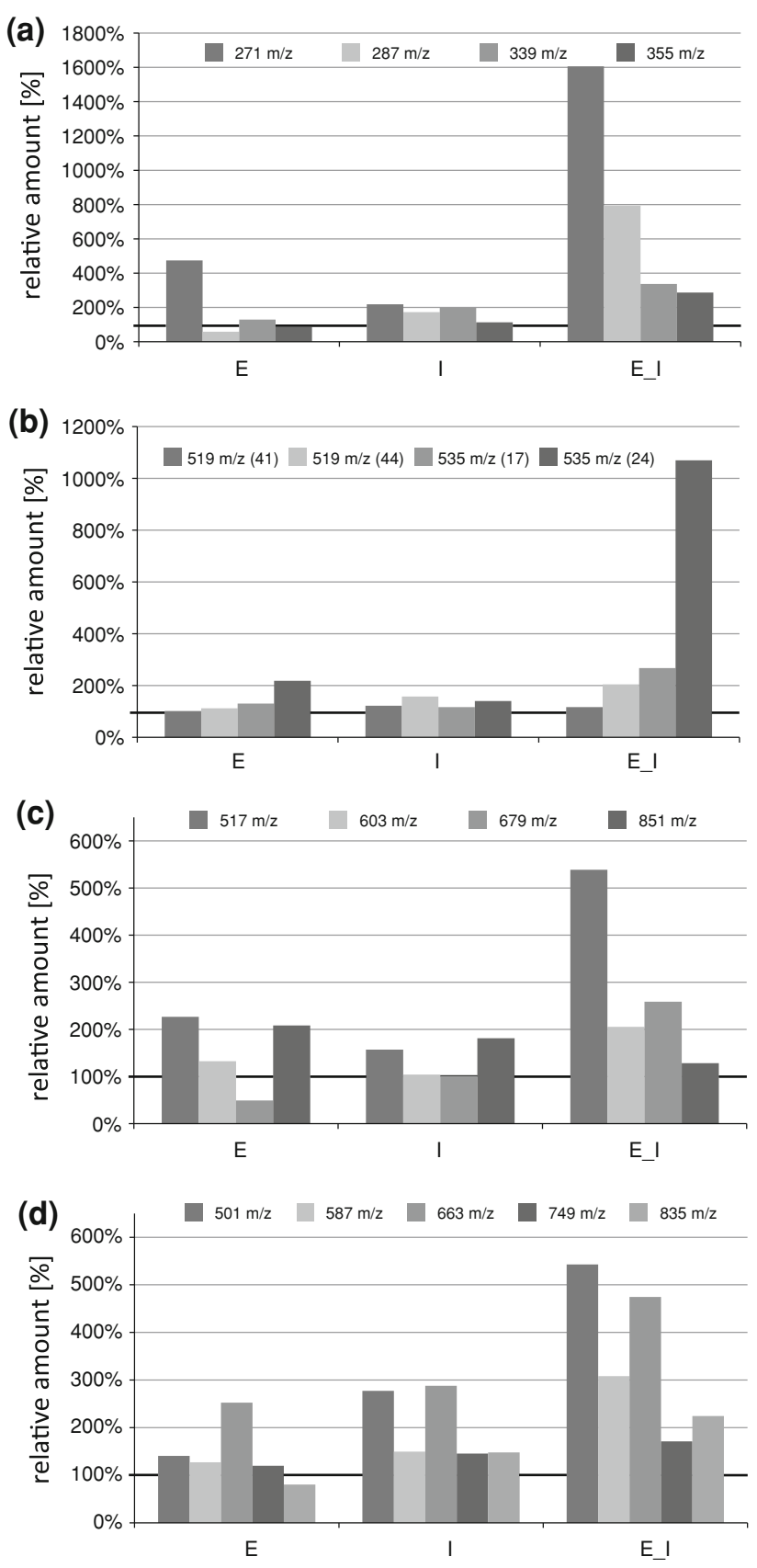

It would be interesting to define the role of the acylation of the studied isoflavones in the stress conditions. At present, it is suggested that the malonylation of flavonoid glycosides plays an important role in intracellular transport of these compounds and the malonylated entities are recognized by MATE transporters and transferred to proper locations (vacuoles) in plant cells (Zhao et al. 2011).

\section{Concluding remarks}

Many of the isoflavone glycoconjugates occur in the L. angustifolius leaves in several isomeric forms. These 
forms differ in the prenylation, glycosylation and/or malonylation pattern and contents of only some of them are changed as a result of infection. From the registered results, we can conclude that especially the malonylation of the glycosylated precursor of antibiotic natural products may play an important role. This may be exemplified by the registration of the increase of contents of only one out of two isomeric malonylated 2'hydroxygenistein glucosides. Generally, it is likely that the changes of only certain isoflavonoids contents and not the overall amount of these compounds are relevant in the plant response to fungal infection. There are major differences in the synthesis of secondary metabolites by lupin plants in response to fungal infection and to treatment with fungal phytotoxic compounds. Spraying lupin plants with toxins accelerates and strengthens their response at the level of synthesis of isoflavone phytoalexins or their precursors. While the first changes in the isoflavone profiles may be observed as early as $12 \mathrm{~h}$ after the phytotoxin deposition on the leaf surface, the altered composition of this pool of secondary metabolites persists in the infected plants for at least several days. In this situation, we can conclude that the perception of MAMPs at the level of low-molecular-weight natural products through the PRRs situated on the cell surface causes changes in the synthesis of plant secondary metabolites that play a role in the protection against fungal infection.

Acknowledgments This study was supported by the Polish Ministry of Science (grant No 7216/BP01/2011/40 and grant UMO-2011/01/N/ NZ2/00025). We are particularly grateful to B. Kalemba and E. Lewartowska (IPG PAS) for maintaining the fungal culture and their skillful help in the infection of lupin plants and purification of phytotoxic compounds. AW is grateful for the scholarship founded within the project from Sub-measure 8.2.2 Human Capital Operational Program, co-financed by European Union Fund.

Open Access This article is distributed under the terms of the Creative Commons Attribution License which permits any use, distribution, and reproduction in any medium, provided the original author(s) and the source are credited.

\section{References}

Abranko, L., Garcia-Reyes, J. F., \& Molina-Diaz, A. (2011). In-source fragmentation and accurate mass analysis of multiclass flavonoid conjugates be electrospray ionization time of flight mass spectrometry. Journal of Mass Spectrometry, 46, 478-488.

Allwood, J. W., Ellis, D. I., \& Goodacre, R. (2008). Metabolomic technologies and their application to the study of plants and plant-host interactions. Physiologia Plantarum, 132, 117-135.

Bednarek, P., Kerhoas, L., Einhorn, J., et al. (2003). Profiling of flavonoid conjugates in Lupinus albus and Lupinus angustifolius responding to biotic and abiotic stimuli. Journal of Chemical Ecology, 29, 1127-1142.

Bednarek, P., \& Osbourn, A. (2009). Plant-Microbe interactions: chemical diversity in plant defense. Science, 324, 746-748.
Boller, T., \& Felix, G. (2009). A renaissance of elicitors: perception of microbe-associated molecular patterns and danger signals by pattern-recognition receptors. Annual Review of Plant Biology, 60, 379-406.

Boller, T., \& He, S. Y. (2009). Innate immunity in plants: an arms race between pattern recognition receptors in plants and effectors in microbial pathogens. Science, 324, 742-744.

Broeckling, C. D., Huhman, D. V., Farag, M. A., et al. (2005). Metabolic profiling of Medicago truncatula cell cultures reveals the effects of biotic and abiotic elicitors on metabolism. Journal of Experimental Botany, 56, 323-336.

Conrath, U. (2011). Molecular aspects of defence priming. Trends in Plant Science, 16, 524-531.

Dixon, R. A., \& Paiva, N. L. (1995). Stress-induced phenylpropanoid metabolism. Plant Cell, 7, 1085-1097.

Djamei, A., Schipper, K., Rabe, F., et al. (2011). Metabolic priming by a secreted fungal effector. Nature, 478, 395-398.

Farag, M. A., Deavours, B. E., de Fatima, A., Naoumkina, M., Dixon, R. A., \& Sumner, L. W. (2009). Integrated metabolite and transcript profiling identify a biosynthetic mechanism for hispidol in Medicago truncatula cell cultures. Plant Physiology, 151, 1096-1113.

Farag, M. A., Huhman, D. V., Dixon, R. A., \& Sumner, L. W. (2008). Metabolomics reveals novel pathways and differential mechanistic and elicitor-specific responses in phenylpropanoid and isoflavonoid biosynthesis in Medicago truncatula cell cultures. Plant Physiology, 146, 387-402.

Frański, R., Bednarek, P., Siatkowska, D., Wojtaszek, P., \& Stobiecki, M. (1999a). Application of mass spectrometry to structural identification of flavonoid monoglycosides isolated from shoot of lupin (Lupinus luteus L.). Acta Biochimica Polonica, 46, 459-473.

Frański, R., Bednarek, P., Wojtaszek, P., \& Stobiecki, M. (1999b). Identification of flavonoid diglycosides in yellow lupin (Lupinus luteus L.) with mass spectrometric techniques. Journal of Mass Spectrometry, 34, 486-495.

Frencel, I. M. (1998). Report on first detection of anthracnose (Colletotrichum gloeosporioides) on lupins in Poland. Plant Disease, 82, 350.

García-Pajón, C. M., \& Collado, I. G. (2003). Secondary metabolites isolated from Colletotrichum species. Natural Product Reports, 20, 426-431.

Gould, K.S. \& Lister, C. (2006). Flavonoid functions in plants. In: Andersen, Ø.M. and Markham, K.R (Eds), Flavonoids chemistry, biochemistry and applications (pp. 397-442). Boca Raton: CRC.

Grotewold, E. (2005). Plant metabolic diversity: a regulatory perspective. Trends in Plant Science, 10, 57-62.

Ingham, J. L., Tahara, S., \& Harborne, J. B. (1983). Fungitoxic isoflavones from Lupinus albus and other Lupinus species. Zeitschrift für Naturforschung A, 38c, 194-200.

Jasiński, M., Kachlicki, P., Rodziewicz, P., Figlerowicz, M., \& Stobiecki, M. (2009). Changes in the profile of flavonoid accumulation in Medicago truncatula leaves during infection with fungal pathogen Phoma medicaginis. Plant Physiology and Biochemistry, 47, 847-853.

Kirk, P. M., Cannon, P. F., Minter, D. W., \& Stalpers, J. A. (2008). The Dictionary of the fungi (10th ed.). Egham: CABI Bioscience.

Lane, G. A., Sutherland, O. R. W., \& Skipp, R. A. (1987). Isoflavonoids as insect feeding deterrents and antifungal components from root of Lupinus angustifolius. Journal of Chemical Ecology, 13, 771-783.

Lommen, A. (2009). MetAlign: interface-driven, versatile metabolomics tool for hyphenated full-scan mass spectrometry data preprocessing. Analytical Chemistry, 81, 3079-3086.

Lozovaya, V. V., Lygin, A. V., Zernova, O. V., Li, S. X., Hartman, G. L., \& Widholm, J. M. (2004). Isoflavonoid accumulation in soybean 
hairy roots upon treatment with Fusarium solani. Plant Physiology and Biochemistry, 42, 671-679.

Luna, E., Bruce, T. J. A., Roberts, M. R., Flors, V., \& Ton, J. (2012). Next-generation systemic acquired resistance. Plant Physiology, 158, 844-853.

Mancilla, G., Jiménez-Teja, D., Femenía-Ríos, M., Macías-Sánchez, A. J., Collado, I. G., \& Hernández-Galán, R. (2009). Novel macrolide from wild strains of the phytopathogen fungus Colletotrichum acutatum. Natural Product Reports, 4, 395-398.

Muth, D., Kachlicki, P., Krajewski, P., Przystalski, M., \& Stobiecki, M. (2009). Differential metabolic response of narrow leafed lupin (Lupinus angustifolius) leaves to infection with Colletotrichum lupini. Metabolomics, 5, 354-362.

Muth, D., Marsden-Edwards, E., Kachlicki, P., \& Stobiecki, M. (2008). Differentiation of isomeric malonylated flavonoid glyconjugates in plant extracts with UPLC-ESI/MS/MS. Phytochemical Analysis, 19, 444-452.

Naoumkina, M., Farag, M. A., Sumner, L. W., Tang, Y., Liu, Ch-J, \& Dixon, R. A. (2007). Different mechanisms for phytoalexin induction by pathogen and wound signals in Medicago truncatula. Proceedings of the National Academy Sciences USA, 104, 17909-17915.

Nirenberg, H. I., Feiler, U., \& Hagedorn, G. (2002). Description of Colletotrichum lupini comb. nov. in modern terms. Mycologia, 94, 307-320.

Schliemann, W., Ammer, C., \& Strack, D. (2008). Metabolite profiling of mycorrhizal roots of Medicago truncatula. Phytochemistry, 69, 112-146.
Stobiecki, M., Staszków, A., Piasecka, A., Garcia-Lopez, P. M., Zamora-Natera, F., \& Kachlicki, P. (2010). LC-MSMS Profiling of flavonoid conjugates in wild Mexican lupine Lupinus reflexus. Journal of Natural Products, 73, 1254-1260.

Suzuki, H., Srinivasa Reddy, M. S., Naoumkina, M., et al. (2005). Methyl jasmonate and yeast elicitor induce differential transcriptional and metabolic re-programming in cell suspension cultures of the model legume Medicago truncatula. Planta, 220, 696-707.

Treutter, D. (2006). Significance of flavonoids in plant resistance: a review. Environmental Chemistry Letters, 4, 147-157.

van Etten, H. D., Mansfield, J. W., Bailey, J. A., \& Farmer, E. E. (1994). Two classes of plant antibiotics: phytoalexins versus phytoanticipines. Plant Cell, 6, 1191-1192.

Veitch, N. C. (2009). Isoflavonoids of the Leguminosae. Natural Products Reports, 26, 776-802.

Wolpert, T. J., Dunkle, L. D., \& Ciuffetti, L. M. (2002). Hostselective toxins and avirulence determinants. What's in a name? Annual Review of Phytopathology, 40, 251-285.

Yu, R. X., Liu, J., True, N., \& Wang, W. (2008). Identification of direct target genes using joint sequence and expression likelihood with application to DAF-16. PLoS ONE, 3(3), e1821.

Zhang, J., Subramanian, S., Stacey, G., \& Yu, O. (2009). Flavons and flavonols play distinct critical roles during nodulation of Medicago truncatula by Sinorhizobium meliloti. Plant Journal, 57, 171-183.

Zhao, J., Huhman, D., Shadle, G., et al. (2011). MATE2 mediates vacuolar sequestration of flavonoid glycosides and glycoside malonates in Medicago truncatula. Plant Cell, 23, 1536-1555. 